\title{
A traditional way to combat against Streptococcus mutans
}

\author{
Research Article
}

\author{
Prabhakar AR ${ }^{1}$, Rekhamani Maganti ${ }^{2 *}$, Mythri ${ }^{3}$, Saraswathi V Naik ${ }^{4}$ \\ 1. Professor and Head, 2. PG Scholar, 3. Senior Lecturer, 4. Reader \\ Department of Pedodontics and Preventive Dentistry, \\ Bapuji Dental College and Hospital, Davangere.
}

\begin{abstract}
Purpose: This study was conducted to evaluate and compare the antimicrobial activity of conventional Glass ionomer cement, Glass ionomer cement (GIC) with $0.1 \%(\mathrm{w} / \mathrm{w})$ epigallocatechin-3-gallate (EGCG) and Glass ionomer cement with $1 \%(\mathrm{w} / \mathrm{w})$ Curcuma longa against streptococcus mutans.

Methods: Children of age group 5-9 years, irrespective of sex, race and socioeconomic status with at least 3 cavitated dentinal lesions in primary molars clinically involving occlusal surface suitable for ART were selected.

The dentinal samples were collected three times from each carious tooth, viz. baseline (before excavation of caries), after hand excavation of caries and after 7 days of restoration. The dentinal samples were subjected to microbiological evaluation for Streptococcus mutans count.

Results: Experimental groups (Group II and group III) showed statistically significant reduction in Streptococcus mutans counts compared to control group (Conventional Glass ionomer cement). Group II i.e. (Glass ionomer cement with $0.1 \%(w / w)$ EGCG) showed significant reduction than Group III i.e. (Glass ionomer cement with $1 \%(\mathrm{w} / \mathrm{w})$ Curcuma longa).

Conclusion: ART technique was successful in reducing the streptococcus mutans load in a carious cavity but significant numbers of residual microbes were still found to be present even after the carious tissue was removed. Restoration of the cavity using EGCG and turmeric modified GIC was able to markedly reduce the S.mutans counts compared to conventional GIC.
\end{abstract}

Keywords: Atraumatic restorative treatment, Glass ionomer cement, epigallocatechin-3-gallate, Curcuma longa, Streptococcus mutans, children.

\section{Introduction}

In the recent years pediatric dentistry has witnessed a tremendous rise in the acceptance and popularity of minimal intervention approaches for management of dental caries most notably the Atraumatic Restorative Treatment (ART) (1). Manual removal of soft demineralized enamel and dentin using hand instruments and restoring them with an adhesive fluoride releasing material, usually glass ionomer cement is the essence of this approach (2).

Whereas even a simple restorative treatment plan can evoke anxiety, ART by virtue of its least intra-operative discomfort (3) qualifies as a suitable option in such anxious patients. Though originally developed for the economically strained, ART in the present day has found applications even in developed nations.

However, the fact that dental hand instruments alone are ineffective in complete removal of carious

*Corresponding Author:

\section{Rekhamani Maganti}

PG scholar,

Dept. of Pedodontics and Preventive Dentistry,

Bapuji Dental College and Hospital, Davangere

Mobile No. +91-9480414409

E-mail: rekhacoolgal.2007@gmail.com dentin in comparison to rotary burs is well known, which consequentially leads to survival of cariogenic bacteria under Glass Ionomer cement (GIC) restorations for up to two years. As a result, cavities treated by ART may have residual infected dentin which if the GIC is unable to arrest, eventually the restoration would fail. Literature supports this finding with reports of failed ART restorations due to secondary caries over six years. Precisely for this reason an improvement in filling materials is desirable which will increase the success rate of ART (4).

By virtue of fluoride release, GIC is assumed to reduce the number of residual bacteria in cavities and also remineralize softened dentin. However, the amount of fluoride release is too small for the remineralization process, and even the anti-bacterial effect is limited only to the region immediately below the restoration. Amongst the various methods that have been used to reduce or eliminate microorganisms underneath GIC restorations, one which is in vogue currently is addition of antibacterial agents to GIC (5).

In the last few decades there has been an emerging trend of seeking natural remedies in medical and dental therapeutics, termed as "phytotherapeutics" or "ethnopharmacology". Traditional medicines are inexpensive and believed to be beneficial. The use of plants and herbs for dental care is common indigenous system of medicine (6). 
Tea, the infusion of dried leaves of camellia sinesis, is the most popular beverage in the world. Reports indicate that drinking tea could decrease dental caries in humans and laboratory animals. Epigallocatechin-3-gallate (EGCG) the major polyphenol present in green tea has been known to contain potential health promoting ingredients. EGCG could be promising as a cariostatic agent because of its antimicrobial activity and various biological effects on oral streptococci (7).

Turmeric (Curcuma longa L), a traditional Indian household herb commonly known as "HALDI" is a perennial plant, the tubers of which when dried can be made into powder. The active constituent of turmeric is known as "curcumin" (8). It has a long history of medicinal use especially in Ayurveda, Siddha and Unani systems for its anti-inflammatory, anti-oxidant, anti-microbial and anti allergic properties along with other beneficial therapeutic effects (9).

Improved antibacterial activity of restorative materials would be advantageous to eliminate the risk of further demineralization and cavitation thus increasing the longevity of restorations. Hence the present study was designed in vivo to compare whether the incorporation of epigallocatechin-3-gallate and Curcuma longa into the conventional Glass ionomer cement has effect on inhibition of streptococcus mutans and increasing the longevity of ART restorations.

\section{Materials and methods}

The present in vivo study was conducted in the Department of Pedodontics and Preventive dentistry, Bapuji Dental College and Hospital Davangere. In association with Department of Industrial pharmacy, Bapuji College of Pharmacy Davangere and Department of Oral Pathology, Bapuji Dental College and Hospital Davangere.

The participants in the study were selected from the outpatient clinic of the Department of Pedodontics and Preventive Dentistry. Written informed consent was procured from parents of all participants prior to the participation in the study.

\section{Criteria to select the subjects were: Inclusion criteria:}

- Children of age group 5-9 years, irrespective of sex, race and socioeconomic status

- Children with at least 3 cavitated dentinal lesions in primary molars clinically involving occlusal surface suitable for ART.

\section{Exclusion criteria:}

- Teeth with deep dentinal lesions involving pulp, periapical abscess, pain or swelling and developmental disorders

- Children with systemic illness.

The study groups which were used in the study were:

- Group 1(control group): Conventional glass ionomer cement (GC Fuji IX)

- Group 2 :Glass ionomer cement(GC Fuji IX ) with $0.1 \%(\mathrm{w} / \mathrm{w})$ epigallocatechin-3-gallate
- Group 3:Glass ionomer cement(GC Fuji IX ) with $1 \%(\mathrm{w} / \mathrm{w})$ Curcuma longa

\section{Procedure:}

The following principal steps of ART were carried out (Manual for the ART approach to control dental caries, WHO 1997):

1. Isolation of tooth with rubber dam.

2. The tooth surface to be treated was cleaned with wet cotton pellet.

3. The entrance of the lesion was widened. If the lesion was small, the following procedure was used to widen the entrance of cavity i.e. the working tip of the enamel hatchet was inserted in the entrance of the cavity and was rotated backwards and forwards scraping along the walls thus creating an opening large enough for placement of small head of spoon excavator.

4. Carious dentin was removed with a thin sharp excavator.

5. GIC was mixed according to manufacturer's instructions.

6. The mixed GIC was inserted into the cavity.

7. Petroleum jelly was applied to gloved finger

8. Petroleum jelly coated gloved finger was pressed on top of the entire occlusal surface and slight pressure was applied.

9. The bite was checked using articulating paper.

10. Excess material was removed using BP blade.

11.The patient was instructed not to eat for one hour.

All the carious lesions were restored for an individual subject at the same appointment

\section{Dentin sampling procedure}

Patients were selected as per the above mentioned criteria and informed consent was obtained from the accompanying parent after explaining the procedure.

In each patient three cavitated lesions were selected and isolated with rubber dam to prevent contamination. A baseline sample of the carious lesion was obtained from the centre of each lesion for microbial analysis, using a sterile spoon excavator prior to excavation of caries (Fig I).

The lesion was then treated for caries removal by Atraumatic restorative treatment [ART] using sharp spoon excavator (1).

After the removal of caries, a second dentin sample for microbial evaluation was collected using another sterile spoon excavator from the hard dentin (Fig II). The cavity depth was measured using a sterile endodontic file with an adapted stopper (1).The measurement was recorded for each tooth (Fig III).

The cavities were then restored randomly i.e. one of the cavities was restored by using conventional Glass ionomer Cement, second was restored with a glass ionomer cement containing epigallocatechin-3-gallate. Third was restored with a Glass ionomer Cement containing Curcuma longa(Fig IV).

The patients were then recalled after 7 days interval. The restorations were removed with the help of high speed bur to the specified premeasured depth in the 
centre of the restoration, wide enough to collect dentin sample using spoon excavator (1) (Fig V).

New dentin samples were collected for microbial analysis using a spoon excavator from the same place where previous samples were collected (1) (Fig VI). After collection of the third sample, the teeth were restored with conventional GIC.

The dentinal samples were collected three times from each carious tooth, i.e. baseline (before excavation of caries), after hand excavation of caries and after 7 days of restoration. The dentinal samples were subjected to microbiological evaluation for Streptococcus mutans count.

\section{Microbiological procedures:}

Transportation of the samples to the microbiology laboratory was done at room temperature $\left(37^{0}\right)$. The samples were colour coded and processed randomly.

The samples were then centrifuged to disperse bacterial aggregates and $0.1 \mathrm{ml}$ of samples were inoculated onto MS agar supplemented with 15\% sucrose and bacitracin $(0.2 \mathrm{U} / \mathrm{ml})$ (10) Cultivation of microorganism was done by incubating in an incubator for $48 \mathrm{hrs}$ and at the end of two days number of colony forming units were counted using digital colony counter(Fig VII) (S I No 0803010)

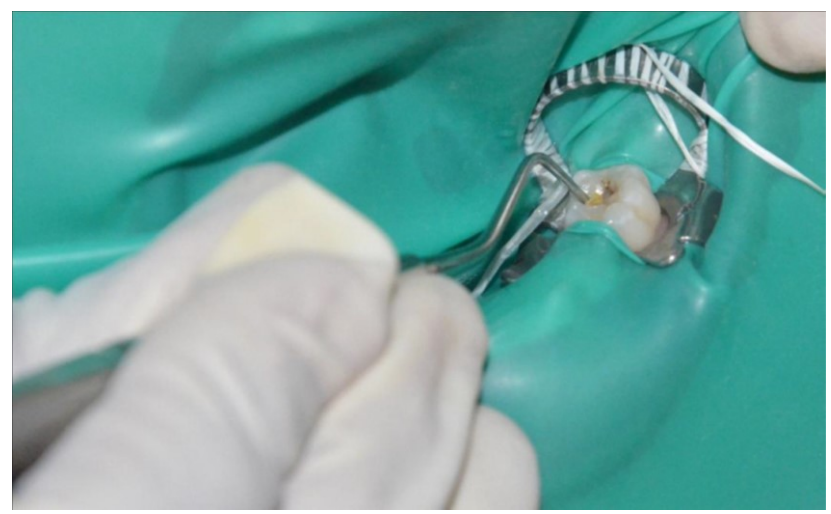

Figure I Collection of sample before excavation of dental caries

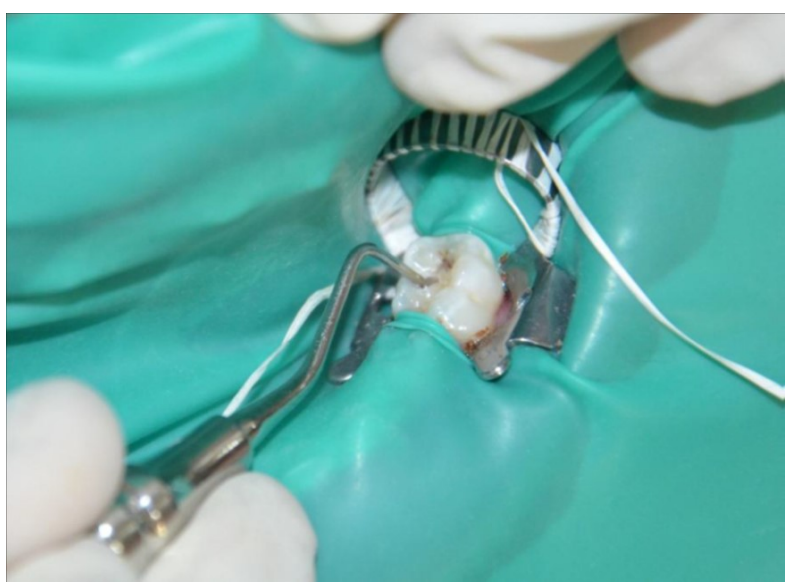

Figure II Sample collection after excavation of dental caries
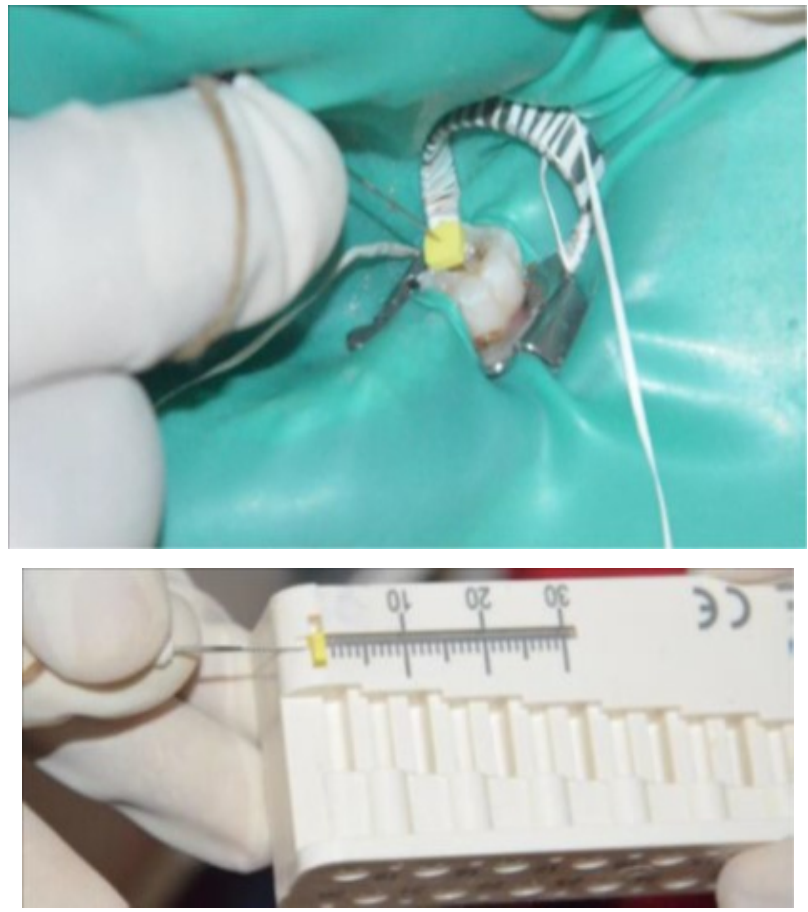

Figure III Measurement of depth of the cavity

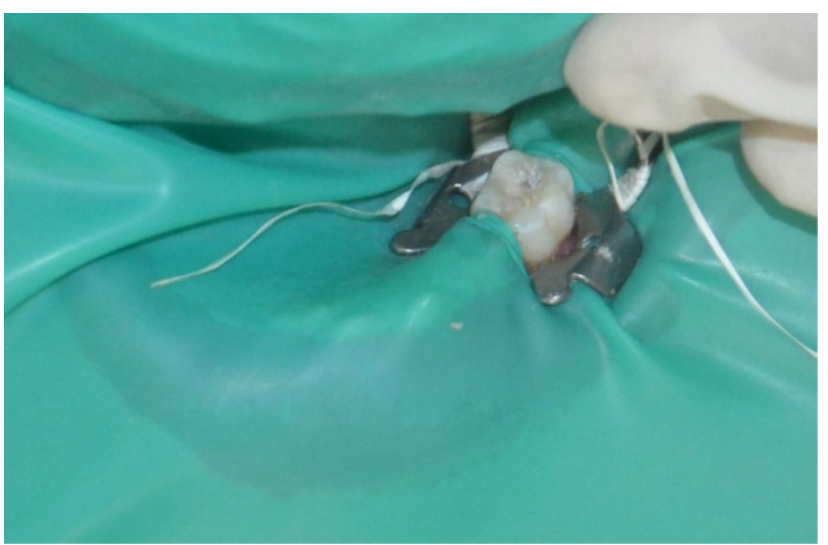

Figure IV Cavity after restoration

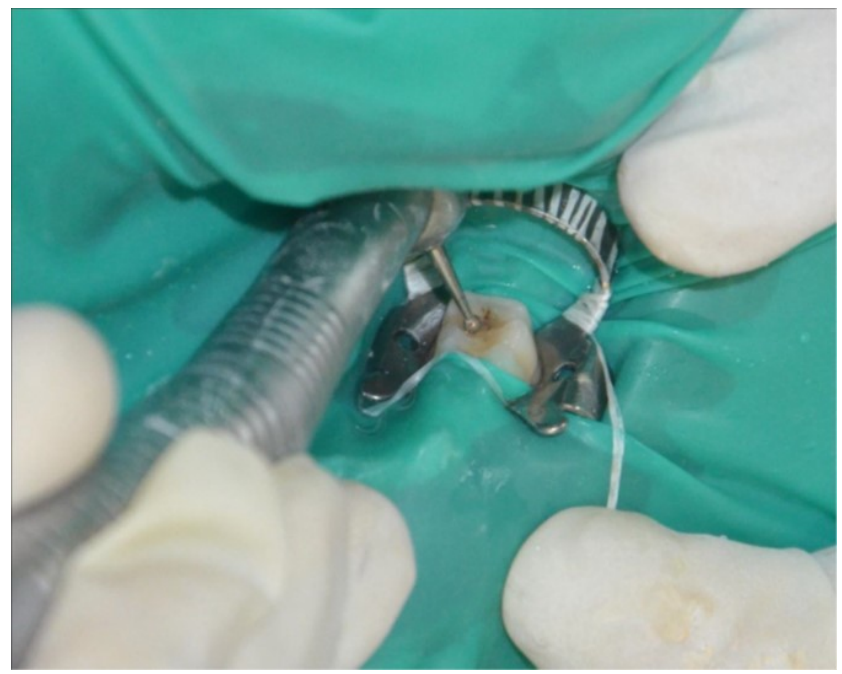

Figure V Removal of restoration after 7 days 


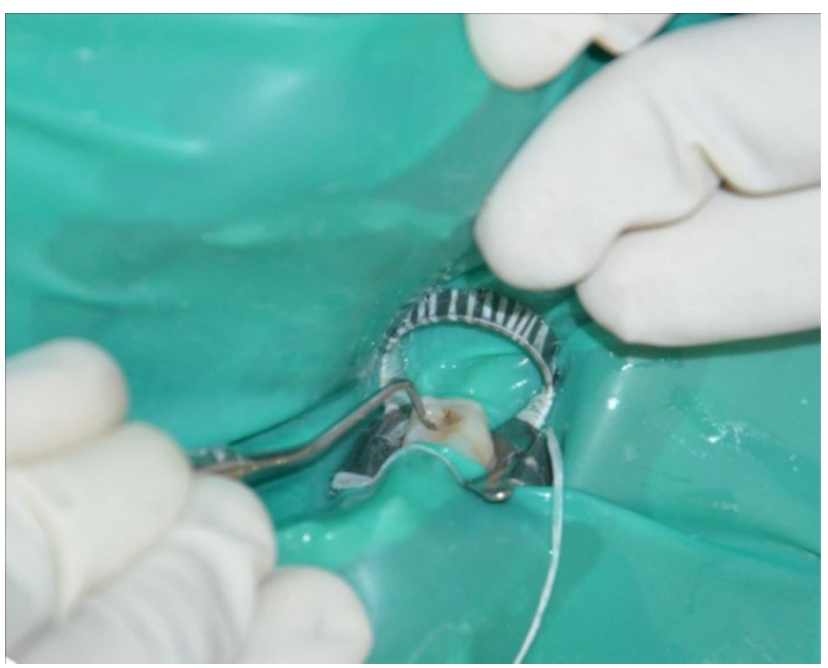

Figure VI Collection of sample after 7 days recall period

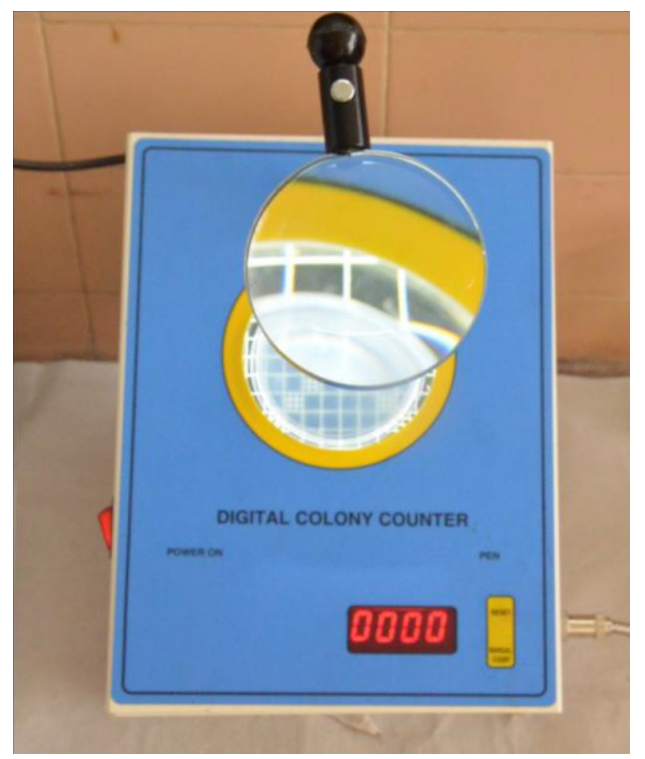

Figure VII S.mutans colonies on digital colony counter.

\section{Statistical analysis}

One way ANOVA was used for simultaneous multiple group comparisons followed by POST-HOCTUKEY test for group wise comparisons, paired t test was used for intra group comparison of changes from base line to 7 days.

\section{Results}

When the mean scores of S.mutans before excavation was observed, the findings were fairly similar for all the three groups, i.e. $183.35 \pm 49.69$ for group I, $163.7 \pm 46.87$ for group II, and $144.35 \pm 36.88$ for group III. After the excavation of the carious lesion, i.e. values representing the efficacy of ART procedure, the reduction in bacterial counts was remarkable for all the three groups i.e. $91.35 \pm 2.25$ for group I, $90 \pm 2.96$ for group II, $90.1 \pm 2.63$ for group III. On recall visits there was reduction in bacterial counts in all groups i.e. $52.65 \pm 11.86$ for group I, $7.15 \pm 7.89$ for group II, and $29.10 \pm 16.11$ for group III, experimental groups showed statistically significant reduction in bacterial counts compared to control group. Group II i.e. (Glass ionomer cement with $0.1 \%(\mathrm{w} / \mathrm{w})$ epigallocatechin-3gallate) showed significant reduction than group III i.e. (Glass ionomer cement with 1\% (w/w) Curcuma longa (Table I \& Graph I).

\section{Discussion}

Recent concepts encompassing the MID philosophy emphasize the need to create a favorable environment for arresting the progress of caries with bare minimum operative intervention. One such minimal invasive treatment approach is Atraumatic Restorative Treatment (ART).During the last 25 years, the ART approach has become a major asset in global oral health and has risen to its present position because its originators, from time zero, emphasized the need for research into its various aspects to accompany its development (11).

However, dental hand instruments alone do not remove carious dentin effectively and cariogenic bacteria can survive under GIC restoration. While using minimally invasive techniques such as ART, the limitations in terms of accessibility and fatigue of hand and wrists, increase the risk of incomplete excavation, consequently, cavities treated by ART may have residual infected dentin and if GIC is unable to arrest the carious process, the restoration may fail (12).

GICs are capable of releasing fluoride, which contributes to some reduction in the number of residual bacteria in cavities as well as remineralization of softened dentin. Fuji IX has been reported to release approximately $10 \mathrm{ppm}$ fluoride during $48 \mathrm{~h}$, however, such amounts of Fluoride is minuscule to exhibit antibacterial effects (13).

Several endeavors at developing GIC with enhanced antibacterial effects by addition of Chlorhexidine hydrochloride, cetyl pyridinum chloride, cetrimide, benzalkonium chloride, triple antibiotics, triclosan, quaternary ammonium salt (PQAS) have all shown to enhance the antibacterial activity of GIC, but the ease of availability, cost, effect on its physical properties as well potential toxic side effects of the additives cannot be ruled out (14).Traditional medicines are inexpensive, less toxic and believed to be beneficial. The use of plants and herbs for dental care is a very common indigenous system of medicine.

Although EGCG and Curcuma longa have been incorporated to GIC previously, the authors had evaluated various parameters in vitro. Dental literature has reported no studies on incorporation of EGCG and Curcuma with GIC for evaluating antimicrobial efficacy against streptococcus mutans in vivo.

Jieqiong $\mathrm{H}$ et al concluded that GIC-containing $0.1 \%(\mathrm{w} / \mathrm{w})$ EGCG is a promising restorative material with improved mechanical properties and a tendency towards preferable antibacterial properties. Hence in the present study $0.1 \% \mathrm{w} / \mathrm{w}$ epigallocatechin-3-gallate (EGCG) was added to conventional GIC (17).

Prabhakar A R et al concluded that incorporation of turmeric at concentration of $1 \%$ has the potential to enhance the antibacterial activity of GIC as well as fluoride release without compromising on its physical 
$\underline{\text { Table I: Inter group comparison of Mean colony counts for S.mutans }}$

\begin{tabular}{|c|c|c|c|c|c|c|c|c|c|c|c|c|c|}
\hline \multirow{2}{*}{\multicolumn{2}{|c|}{\begin{tabular}{|l} 
\\
GROUP
\end{tabular}}} & \multicolumn{2}{|c|}{ Before (B) } & \multicolumn{2}{|c|}{ After (A) } & \multicolumn{2}{|c|}{ Recall (R) } & \multicolumn{2}{|c|}{ B-A } & \multicolumn{2}{|l|}{ A-R } & \multicolumn{2}{|l|}{ B-R } \\
\hline & & $\begin{array}{l}\text { Mea } \\
n\end{array}$ & $\mathrm{SD}$ & $\begin{array}{l}\mathrm{Me} \\
\text { an }\end{array}$ & $\mathrm{SD}$ & $\begin{array}{l}\mathrm{Me} \\
\text { an }\end{array}$ & $\overline{\mathrm{SD}}$ & $\begin{array}{l}\mathrm{Me} \\
\text { an }\end{array}$ & $\mathrm{SD}$ & $\begin{array}{l}\mathrm{Me} \\
\text { an }\end{array}$ & $\mathrm{SD}$ & $\begin{array}{l}\text { Mea } \\
n\end{array}$ & $\overline{S D}$ \\
\hline \multicolumn{2}{|l|}{ Group I } & $\begin{array}{l}183 . \\
35\end{array}$ & $\begin{array}{l}49 . \\
69\end{array}$ & $\begin{array}{l}91 . \\
35\end{array}$ & $\begin{array}{l}2.2 \\
5\end{array}$ & $\begin{array}{l}52 . \\
65\end{array}$ & $\begin{array}{l}11 . \\
86\end{array}$ & 92 & $\begin{array}{l}49 . \\
45\end{array}$ & $\begin{array}{l}38 . \\
7\end{array}$ & $\begin{array}{l}11 . \\
85\end{array}$ & $\begin{array}{l}130 . \\
7\end{array}$ & $\begin{array}{l}45 . \\
47\end{array}$ \\
\hline \multicolumn{2}{|l|}{ Group II } & $\begin{array}{l}163 . \\
7\end{array}$ & $\begin{array}{l}46 . \\
87\end{array}$ & 90 & $\begin{array}{l}2.9 \\
6\end{array}$ & $\begin{array}{l}7.1 \\
5\end{array}$ & $\begin{array}{l}7.8 \\
9\end{array}$ & $\begin{array}{l}73 . \\
7\end{array}$ & $\begin{array}{l}45 . \\
18\end{array}$ & $\begin{array}{l}82 . \\
85\end{array}$ & 8.2 & $\begin{array}{l}156 . \\
55\end{array}$ & $\begin{array}{l}45 . \\
86\end{array}$ \\
\hline \multicolumn{2}{|l|}{ Group III } & $\begin{array}{l}144 . \\
35\end{array}$ & $\begin{array}{l}36 . \\
88\end{array}$ & $\begin{array}{l}90 . \\
1\end{array}$ & $\begin{array}{l}2.6 \\
3\end{array}$ & $\begin{array}{l}29 . \\
1\end{array}$ & $\begin{array}{l}16 . \\
11\end{array}$ & $\begin{array}{l}54 . \\
25\end{array}$ & $\begin{array}{l}36 . \\
77\end{array}$ & 61 & $\begin{array}{l}15 . \\
98\end{array}$ & $\begin{array}{l}115 . \\
25\end{array}$ & $\begin{array}{l}28 . \\
99\end{array}$ \\
\hline \multirow[t]{2}{*}{ ANOVA } & $\bar{F}$ & \multicolumn{2}{|c|}{3.786} & \multicolumn{2}{|c|}{$\begin{array}{l}1.636 \\
\end{array}$} & \multicolumn{2}{|c|}{67.16} & \multicolumn{2}{|c|}{3.662} & \multicolumn{2}{|c|}{63.139} & \multicolumn{2}{|c|}{5.213} \\
\hline & $\begin{array}{l}\text { p- } \\
\text { val } \\
\text { ue }\end{array}$ & \multicolumn{2}{|l|}{0.029} & \multicolumn{2}{|c|}{0.204} & \multicolumn{2}{|c|}{0.001} & \multicolumn{2}{|c|}{0.03} & \multicolumn{2}{|c|}{0.001} & \multicolumn{2}{|c|}{0.008} \\
\hline \multirow{3}{*}{$\begin{array}{l}\text { Difference } \\
\text { between } \\
\text { groups }\end{array}$} & $\begin{array}{ll}\text { I } & \text { V/ } \\
\text { s II }\end{array}$ & \multicolumn{2}{|l|}{0.35} & \multicolumn{2}{|c|}{0.24} & \multicolumn{2}{|c|}{0.001} & \multicolumn{2}{|c|}{0.39} & \multicolumn{2}{|c|}{0.001} & \multicolumn{2}{|l|}{0.12} \\
\hline & $\begin{array}{lll}\text { I } & \text { v/ } \\
\text { s } & \text { III }\end{array}$ & \multicolumn{2}{|l|}{0.02} & \multicolumn{2}{|c|}{0.29} & \multicolumn{2}{|c|}{0.001} & \multicolumn{2}{|c|}{0.02} & \multicolumn{2}{|c|}{0.001} & \multicolumn{2}{|l|}{0.46} \\
\hline & $\begin{array}{l}\text { II } \\
\text { V/s } \\
\text { III }\end{array}$ & \multicolumn{2}{|l|}{0.36} & 0.93 & & 0.00 & & 0.35 & & 0.00 & & 0.00 & \\
\hline
\end{tabular}

GRAPH I: Intergroup comparison of Mean Colony forming units of S.mutans Before, After and $\underline{\text { Recall Samples }}$

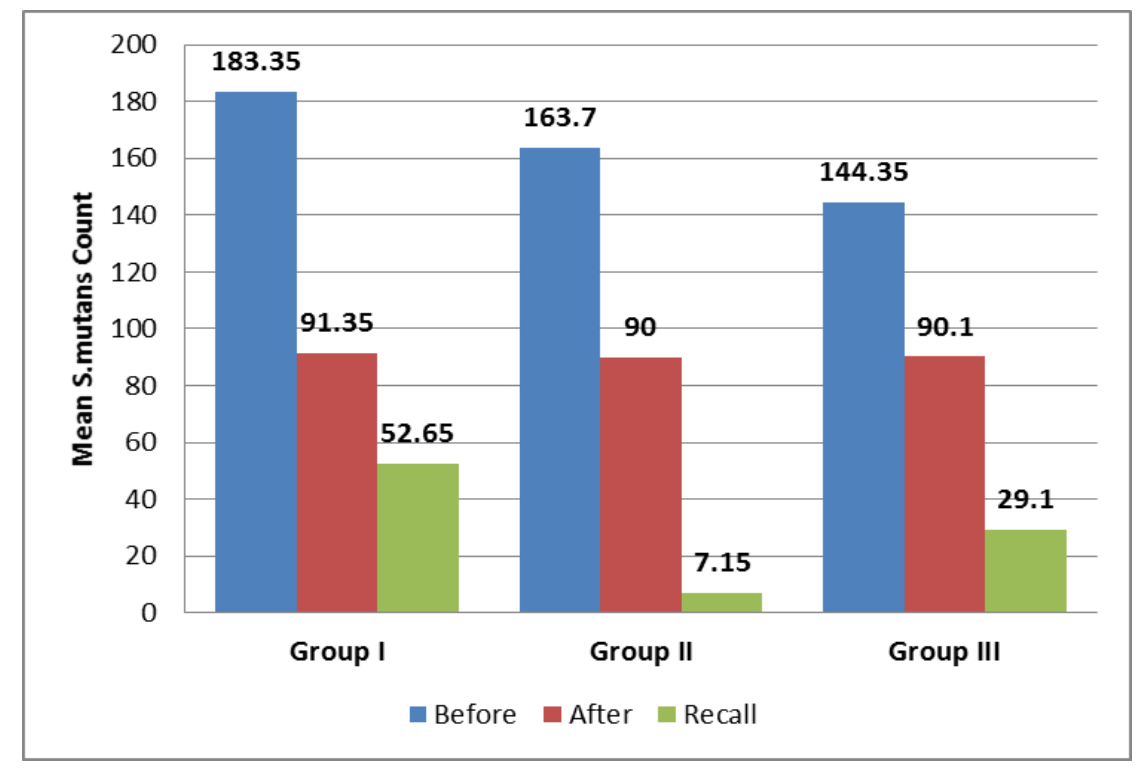

abilities i.e. shear bond strength, microleakage and setting time. Hence in the present study $1 \% \mathrm{w} / \mathrm{w}$ turmeric was added to conventional glass ionomer cement (14).

In the present study a significant load of S.mutans was recovered at baseline and was fairly similar in the infected dentin samples for all the three groups. After the removal of carious dentin using ART, the affected dentin samples also had similar results among all the three groups, with a statistically significant reduction compared to the baseline colony counts.

Hence the efficacy of ART procedure itself was quite successful in reducing the bacterial counts of a carious cavity but it however failed to eliminate them completely.

The finding in the present study is in line with those reported by others, where $63 \%$ isolates of S.mutans strains were reduced to $35 \%$. The significant 
decrease in bacteria after manual cavity preparation demonstrates the reliability of a standardized ART technique, yet the presence of S.mutans strains show that the effectiveness of the ART procedure can vary during treatment and between dental practitioners (15). The techniques used for caries removal also affect the treatment outcome and has been accounted for in various studies.

In the present study the number of S.mutans counts on the recall visits i.e. 7 days reduced significantly in all the 3 groups but there was statistically significant reduction in counts among experimental groups than the control group. Comparing within the experimental Groups, Group II (Glass ionomer cement with $0.1 \%(\mathrm{w} / \mathrm{w})$ epigallocatechin-3gallate) showed statistically significant reduction in S.mutans counts compared to group III (Glass ionomer cement with $1 \%$ (w/w) Curcuma longa).

The increased reduction in S. mutans counts in Group II can be attributed to the antibacterial properties of EGCG. EGCG at sub lethal levels has the ability to reduce $\mathrm{S}$. mutans biofilm formation by suppressing gtf (glucosyl transferase) expression associated with cell adherence and biofilm formation. It possesses great antioxidant activity. It could reduce the production of acidic compounds and manage antibacterial effects against oral streptococci via the non-reversible damage of the microbial cytoplasmic membrane. Some studies have demonstrated that EGCG can exhibit a wide range of physiological effects on S. mutans and particularly on virulence factors associated with its acidogenicity and acidurity. The concentrations of EGCG required for this inhibition in some reports were often in the $\mathrm{mg} / \mathrm{ml}$ range, while others reported MIC between 50 and 500 $\mathrm{mg} / \mathrm{ml}$ for the inhibition of growth of oral streptococci. A study conducted by Jiovanne Rabelo Neri et al found that EGCG incorporated into dental adhesives at the concentration of $200 \mathrm{mg} / \mathrm{ml}$ provided satisfactory antimicrobial function against $\mathrm{S}$. mutans(16) This is in accordance with the present study.

Group III also showed a significant reduction in S.mutans counts compared from after excavation of caries to the recall visit. This significant reduction in bacterial counts can be attributed to Curcumin which is a naturally occurring polyphenolic compound present in Curcuma longa. It exhibits antimicrobial and anticancer activity by hindering the growth of bacterial and cancer cells. Curcumin can inhibit S. mutans sortase A activity. Sortase A is an enzyme responsible for the covalent attachment of Pac proteins to the cell wall in Streptococcus mutans. It has been shown to play a role in modulating the surface properties and the biofilm formation and influence the cariogenicity of S. mutans (17). In a study conducted by (Prabhakar A R et al. 2014) it is shown that turmeric when incorporated in GIC exhibited statistically significant inhibitory zones against $\mathrm{S}$ mutans after 48 hours. In the same study it was also noticed that there was highly significant increase in the release of fluoride from the turmeric groups when compared to the control group both at 24 hours and 7 days intervals. The amount of fluoride ions released had a linear increase with the increase in the concentration of turmeric in the cement.

The reason for increased efficacy of EGCG over turmeric could be due to decrease in the availability of 'free' turmeric (below minimum concentration levels) at 7 days. The results of this study can be compared with previous in vitro study which demonstrated that turmeric was effective in inhibiting bacterial growth after 48 hours, but all the turmeric containing specimens showed no change in the zones of inhibition at 7 days (14). This decrease in turmeric could in turn be a result of the loss of material by elution, or perhaps may be due to the ability of turmeric to form insoluble salts with the GIC, in accordance with the suggestion made by Ribeiro and Ericson with regards to chlorhexidine

\section{Conclusion} study:

The following conclusions can be drawn from the

- ART procedure itself was quite successful in reducing the $\mathrm{S}$. mutans counts of a carious cavity but it however could not eliminate them completely

- Incorporation of $0.1 \%(\mathrm{w} / \mathrm{w})$ epigallocatechin-3gallate and $1 \%(\mathrm{w} / \mathrm{w})$ Curcuma longa to conventional GIC enhanced the antimicrobial efficacy of GIC against streptococcus mutans.

- Among epigallocatechin-3-gallate and Curcuma longa, epigallocatechin-3-gallate is more efficacious in reducing streptococcus mutans counts.

- Within the limitations of the present study, it may be concluded that incorporation of EGCG and turmeric in conventional Glass ionomer cement had superior effect in reducing streptococcus mutans counts left under restorations compared to Conventional GIC restorations. Hence we recommend EGCG and turmeric modified glass ionomer cements as suitable restorative materials for use in minimally invasive dentistry which is in vogue of today's preventive dental practice.

\section{References}

1) Frencken JE, Imazato $\mathrm{S}$, Toi $\mathrm{C}$, Mulder J, Mickenautsch S, Takahashi Y, Ebisu S. Antibacterial effect of chlorhexidine- containing glass ionomer cement in vivo: a pilot study. Caries Res. 2007; 41(2):102-7.

2) hluwalia P, Chopra S, Thomas AM. Strength characteristics and marginal sealing ability of chlorhexidine-modified glass ionomer cement: an in vitro study. J Indian Soc Pedod Prev Dent. 2012 Jan-Mar; 30(1):41-6

3) Raggio DP, Hesse D, Lenzi TL, A B Guglielmi C, Braga MM. Is Atraumatic restorative treatment an option for restoring occlusoproximal caries lesions in primary teeth? A systematic review and metaanalysis. Int J Paediatr Dent. 2013Nov;23(6):43543.

4) Yesilyurt C, Er K, Tasdemir T, Buruk K, Celik D. Antibacterial activity and physical properties of 
glass-ionomer cements containing antibiotics. Oper Dent. 2009 Jan-Feb; 34(1):18-23.

5) Ersin NK, Aykut A, Candan U, Onçağ O, Eronat C, Kose T. The effect of a chlorhexidine containing cavity disinfectant on the clinical performance of high-viscosity glass-ionomer cement following ART: 24-month results. Am J Dent. 2008 Feb; 21 (1):39-43.

6) Neelakantan $P$, Jagannathan $N$, Nazar N. Ethnopharmacological approach in endodontic treatment: A Focused review. Int J Drug Res. 2011; 3:68-77

7) $\mathrm{Hu}$ J, Du X, Huang C, Fu D, Ouyang X, Wang Y. Antibacterial and physical properties of EGCGcontaining glass ionomer cements. J Dent. 2013 Oct; 41(10):927-34

8) Chaturvedi TP. Uses of turmeric in dentistry: an update. Indian J Dent Res. 2009 Jan-Mar; 20 (1):107-9.

9) Mishra S, Palanivelu K. The effect of curcumin (turmeric) on Alzheimer's disease: An overview. Ann Indian Acad Neurol. 2008 Jan;11(1):13-9.

10) Ersin N K, Uzel A, Aykut A, Candan U. Inhibition of cultivable bacteria by chlorhexidine treatment of dentin lesions treated with the ART technique. Caries Res 2006;40:172-7

11) Frencken JE, Leal SC, Navarro MF. Twenty-fiveyear atraumatic restorative treatment (ART) approach: a comprehensive overview. Clin Oral Investig. 2012 Oct;16(5):1337-46.
12) Yip HK, Smales RJ, Yu C, Gao XJ, Deng DM. Comparison of atraumatic restorative treatment and conventional cavity preparations for glass-ionomer restorations in primary molars: one-year results. Quintessence Int. 2002 Jan;33(1):17-21.

13) Takahashi Y, Imazato S, Kaneshiro AV, Ebisu S, Frencken JE, Tay FR. Antibacterial effects and physical properties of glass-ionomer cements containing chlorhexidine for the ART approach. Dent Mater. 2006 Jul;22(7):647-52.

14) Prabhakar AR, Chandrashekar MY, Karuna YM, Mythri P.Effect of Turmeric incorporation on fluoride release, Antibacterial activity and Physical properties of glass ionomer cement An in-vitro comparative study. Int J ayur Med.2014;5(1):91101.

15) Toi CS, Bönecker M, Cleaton-Jones PE. Mutans streptococci strains prevalence before and after cavity preparation during Atraumatic Restorative Treatment. Oral Microbiol Immunol. 2003 Jun;18 (3):160-4.

16) Neri JR, Yamauti M, Feitosa VP, Pires APM, Araujio RD, Santiago SL. Physicochemical Properties of a Methacrylate - Based Dental Adhesive Incorporated with Epigallocatechin - 3 gallate. Braz Dent Jol.2014;25(6):528-531.

17) $\mathrm{Hu} \mathrm{P}$, Huang $\mathrm{P}$, Chen MW. Curcumin reduces Streptococcus mutans biofilm formation by inhibiting sortase A activity. Arch Oral Biol. 2013 Oct;58(10):1343-8. 